\title{
An Integrated Characterization of Jujube (Ziziphus jujuba Mill.) Grown in the North Adriatic Region
}

\author{
Ana Miklavčič Višnjevec ${ }^{1}$ \\ Alenka Baruca Arbeiter', \\ Matjaž Hladnik', Ajda \\ Ota², Mihaela Skrt², Bojan \\ Butinar ${ }^{3}$, Marijan Nečemer ${ }^{4}$, \\ Marin Krapac ${ }^{5}$, Dean Ban ${ }^{5}$, \\ Milena Bučar-Miklavčič ${ }^{3}$, \\ Nataša Poklar Ulrih² \\ and Dunja Bandelj ${ }^{1 *}$
}

${ }^{1}$ Faculty of Mathematics, Natural Sciences and Information Technologies, University of Primorska, Glagoljaška 8, 6000 Koper, Slovenia 2Department of Food Science and Technology, Biotechnical Faculty, Jamnikarjeva ulica 101, 1000 Ljubljana, Slovenia

${ }^{3}$ Science and Research Centre Koper, Garibaldijeva 1, 6000 Koper, Slovenia ${ }^{4}$ Department of Environmental Sciences, Jamova cesta 39, 1000 Ljubljana, Slovenia

${ }^{5}$ Institute of Agriculture and Tourism, UI. Karla Huguesa 8, 52440 Poreč, Croatia

Received: 24 June 2018 Accepted: 17 December 2018

\footnotetext{
*Corresponding author:

Phone: +38656117570

Fax: +38656117571

E-mail: dunja.bandelj@upr.si

ORCID IDs: 0000-0003-4259-6191

(Miklavčič Višnjevec), 0000-0002-5535-3546 (Baruca Arbeiter), 0000-0002-

-7955-2873 (Hladnik), 0000-0001-6309-6669 (Ota), 0000-0002-9755-9673 (Skrt) 0000-0002-2018-632X (Butinar), 0000-0003-0547-104X (Nečemer), 0000-0003-0741-388X (Krapac), 0000-0002-7335-637X (Ban), 0000-0002-4929-2249 (Bučar-Miklavčič), 0000-0002-2731-9973 (Poklar Ulrih), 0000-0001-6927-9642 (Bandelj)
}

\section{SUMMARY}

Jujube (Ziziphus jujuba Mill.) has favourable horticultural properties including adaptation to arid conditions, abiotic and biotic stresses, as well as positive impact on human health. The present study describes the characterization of genetic diversity of the germplasm of jujube from the Istrian peninsula, the determination of important chemical compounds, antioxidative properties in relation to antibacterial and antifungal activities of jujube fruit extracts, and the determination of nutritional properties of jujube fruit. The results of the genetic analysis showed that most of the samples from the Istrian peninsula belong to two recently introduced varieties, 'Li' and 'Lang', and the most widespread local variety 'Navadna žižola'. The local variety has smaller fruit than the 'Li' and 'Lang' varieties, with thick and fleshy mesocarp. Chemical analysis indicated that fruits of the local variety contained a valuable source of dietary fibre $((9.7 \pm 0.6) \mathrm{g} / 100 \mathrm{~g})$ and were rich in minerals such as (in $\mathrm{g} / 100 \mathrm{~g}$ dry mass): potassium ( $829 \pm 51$ ), calcium (177 \pm 11 ) and phosphorus (129 \pm 19 ). Aqueous extracts showed slight antibacterial activity, while ethanol extracts had higher mass fractions of phenolic compounds (expressed as gallic acid equivalents (GAE), $5.8-8.7 \mathrm{mg} / \mathrm{g}$ ) than the aqueous extracts, but did not show antimicrobial activity. Compounds other than phenolic compounds in jujube fruit may be more biologically active. Based on the results of these analyses, the local Istrian jujube variety is a promising candidate for cultivation potential.

Key words: Ziziphus jujuba Mill., phenolic compounds, antioxidative properties, nutritional properties, antimicrobial activity, genetic diversity

\section{INTRODUCTION}

Smaller fruits like quince, rose hip, hawthorn, jujube, etc. are easier to grow and naturally harder, producing a crop even under adverse soil and climatic conditions. Their fruits have unique aromas and tastes and play a vital role in the nutrition and livelihood of some rural and tribal masses, contributing to employment and income generation (1-3). Jujube (Ziziphus jujuba Mill.) is a valuable and economically important fruit tree native to China with a very long tradition of cultivation. It is estimated that its domestication started 7000 years ago, and a complex genetic background of germplasm has been shaped with extensive hybridisation between jujube and its wild relatives (4). Traditionally, jujube varieties are divided in two groups with different mesocarp textures: dry (coarse texture) and fresh (crisp texture). Dry textured jujube represent approx. $80 \%$ of total production. China is the leading producer with 2 million hectares yielding 4.32 million tonnes annually (5).

Favourable horticultural properties, adaptation to arid conditions, abiotic and biotic stresses (2), as well as positive impacts on human health (6-8) have contributed to jujube expansion from its native centre of origin to more than 50 countries throughout the world. It was first spread into neighbouring countries of China and later was introduced to Europe, probably via the famous Silk Road (9). Continuous natural evolution and artificial selection contributed to its wide range of genetic diversity and the number of jujube varieties is estimated to be at 1000 (5). Among all the varieties in China, ten are currently in large-scale commercial cultivation (9), which may possibly result in gene erosion. Of 
great importance to jujube germplasm conservation are two Chinese collections: the National Chinese Jujube Germplasm Repository and the National Foundation for Improved Cultivar of Chinese Jujube (10), which also offers the opportunity for future breeding of jujube varieties and represents cultural heritage of mankind.

Over the last few decades, microsatellite markers have been widely used for fruit genetic diversity studies, population genetic and evolutionary studies, genome analysis, gene mapping and marker-assisted selection (11). Despite the popularity of microsatellites, the first set of 25 jujube microsatellite markers was published only in 2011 (12). Since then, several microsatellites have been isolated and characterized in jujube plants $(4,13)$. Some of these simple sequence repeats (SSRs) have been successfully used for assessment of genetic diversity and population genetic structure in jujube (14).

In recent years, advanced biotechnological tools have contributed to the wealth of genome and transcriptome sequencing data, which represent new approaches to obtain insight in the composition and expression of genes that affect relevant jujube traits. The draft genomes of one of the oldest jujube varieties 'Dongzao' and of a dry jujube variety 'Junzao' have been developed and they offer the first insights into jujube fruit characteristics, including high vitamin C content, its tolerance to particular biotic or abiotic stresses and domestication process that resulted in fruit sweetness and acidity $(15,16)$. More recently, a high-density genetic map was constructed based on single nucleotide polymorphism (SNP) markers which will serve as a unique tool for marker-assisted breeding (17).

Jujube is well-known as a nourishing food and as a traditional medicine in China and many other eastern and south-eastern Asian countries. Its fruits have long been used in folk medicine for liver problems, asthma, fever, nausea, vomiting, abdominal pains, wounds, gout, rheumatism, hypertension and diabetes (18). Recently, numerous in vitro and animal model studies have shown that bioactive compounds and natural substances derived from jujube fruit have potential medicinal and dietary values for humans (6-8).

Jujube fruits are consumed fresh, dried and processed (jams, bread cakes, jelly, etc.). The jujube fruit has a high sugar content and high levels of vitamin C, A, and B complexes, phosphorus and calcium (19). Other important compounds such as alkaloids, flavonoids, sterols, tannins, saponins and unsaturated fatty acids have been detected in different species of the genus Ziziphus (20). Moreover, recent phytochemical and pharmacological studies have shown that polysaccharides are one of the major biologically active components with immunomodulatory, antioxidant, antitumour, hepatoprotective and hypoglycaemic activites (5). In addition, jujube is a source of phenolic compounds that play an important role in resistance to various stresses and contribute to sensory quality and colour (21). They are naturally occurring antioxidants, scavengers of free radicals with pharmacological properties such as anti-inflammatory, anticancer and anti-allergic properties (7).
Although the ecological conditions for the cultivation of jujube on the Istrian peninsula (the northern Adriatic region) are appropriate, the jujube tree is not commonly found in the area. It is typically grown as an ornamental fruit in home gardens. The interest for jujube cultivation in local communities is increasing, and therefore, it is very important to characterize germplasm and the nutritional properties of jujube grown on the Istrian peninsula, and to promote the potential beneficial properties of jujube fruit. The aims of the present study are: (i) characterization of genetic diversity of local jujube germplasm from the Istrian peninsula, (ii) determination of important chemical compounds (phenolic compounds) and antioxidative properties of jujube extracts in relation to antibacterial and antifungal activities, and (iii) determination of nutritional properties of jujube fruit. Based on the results, the most appropriate jujube genotypes for the northern Adriatic region will be selected for further cultivation. Therefore, the main hypothesis of this study is that jujube (Ziziphus jujuba Mill.) grown in the northern Adriatic region has promising cultivation potential due to beneficial nutritional and antimicrobial properties.

\section{MATERIALS AND METHODS}

\section{Plant material and collection sites}

A total of 18 Ziziphus jujuba Mill. samples from Slovenian (SVN) and Croatian (HRV) parts of the Istrian peninsula (North Adriatic Sea) were used for genetic characterization (Table 1). The geographic area is characterized as having a sub-Mediterranean climate. Samples with different local names 'Navadna žižola' (Slovenian for common jujube), 'Domaća žižula' (Croatian for domestic jujube), 'Krupnoplodna' (Croatian for thick-fruited), 'Sitnoplodna' (Croatian for thin-fruited) and two internationally known varieties 'Li' and 'Lang' were included in the analysis. Young leaves of the regional jujube germplasm were collected for genetic analysis on family farms. Some samples of the 'Li' and 'Lang' varieties, and thin-fruited jujubes were provided by nursery Skink Ltd. (Rovinj, Croatia) and by nursery Škocjan, Komunala Koper Ltd. (Koper, Slovenia). Chemical and microbiological analyses were performed on six, previously genotyped local samples, named Zj1, Zj2, Zj3, Zj4, Zj5 and Zj6.

Jujube trees selected for this investigation have been managed with classic farming practices typical for this region. The jujube fruits were randomly picked from the canopy in the beginning of November 2014, targeting the physiological ripening period. Sampling was performed in eight locations of Istrian peninsula (Baredi, Izola, Koper, Dobrava, Kampolin, Rovinj, Pobegi and Strunjan). Chemical and microbial analyses were performed on 20 healthy fruits for each sample. The jujube fruit was first separated in endocarp and mesocarp fractions. Endocarps were stored for further determination of fatty acids. 
Table 1. List of jujube samples used for genetic and chemical analysis, including sample code, the collection site and country, variety name and GPS coordinates of the collection site

\begin{tabular}{|c|c|c|c|c|}
\hline Sample code & Collection place, country & Latitude & Longitude & Name of the variety \\
\hline$Z \mathrm{zj} 1^{*}$ & Baredi, SVN & N45³0'53.3" & $\mathrm{E} 13^{\circ} 40^{\prime} 1.2^{\prime \prime}$ & 'Navadna žižola' \\
\hline $\mathrm{Zj} 2^{*}$ & Izola, SVN & $\mathrm{N} 45^{\circ} 32^{\prime} 23.6^{\prime \prime}$ & $\mathrm{E} 13^{\circ} 41^{\prime} 19.2^{\prime \prime}$ & 'Navadna žižola' \\
\hline Zj3* & Koper, SVN & $\mathrm{N} 45^{\circ} 32^{\prime} 4.9^{\prime \prime}$ & $\mathrm{E} 13^{\circ} 41^{\prime} 57.1^{\prime \prime}$ & 'Navadna žižola' \\
\hline $\mathrm{Zj} 4^{*}$ & Dobrava, SVN & $\mathrm{N} 45^{\circ} 31^{\prime} 42.6^{\prime \prime}$ & $\mathrm{E} 13^{\circ} 37^{\prime} 41^{\prime \prime}$ & 'Navadna žižola' \\
\hline $\mathrm{Zj} 5^{*}$ & Strunjan, SVN & 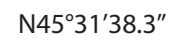 & $\mathrm{E} 13^{\circ} 36^{\prime} 50.4^{\prime \prime}$ & 'Navadna žižola' \\
\hline$Z j 6^{*}$ & Kampolin, SVN & $\mathrm{N} 45^{\circ} 30^{\prime} 42.8^{\prime \prime}$ & $\mathrm{E} 13^{\circ} 36^{\prime} 5.5^{\prime \prime}$ & 'Navadna žižola' \\
\hline Zj7 & $\begin{array}{c}\text { Nursery Skink Ltd., Rovinj, } \\
\text { HRV }\end{array}$ & $\mathrm{N} 45^{\circ} 6^{\prime} 41.2^{\prime \prime}$ & $\mathrm{E} 13^{\circ} 38^{\prime} 12.7^{\prime \prime}$ & 'Krupnoplodna' \\
\hline Zj8 & $\begin{array}{c}\text { Nursery Skink Ltd., Rovinj, } \\
\text { HRV }\end{array}$ & $\mathrm{N} 45^{\circ} 6^{\prime} 41.2^{\prime \prime}$ & $\mathrm{E} 13^{\circ} 38^{\prime} 12.7^{\prime \prime}$ & 'Lang' \\
\hline Zj9 & $\begin{array}{c}\text { Nursery Skink Ltd., Rovinj, } \\
\text { HRV }\end{array}$ & $\mathrm{N} 45^{\circ} 6^{\prime} 39.1^{\prime \prime}$ & $\mathrm{E} 13^{\circ} 38^{\prime} 10.4^{\prime \prime}$ & $\begin{array}{l}\text { 'Domaća žižula' } \\
\text { (mother plant) }\end{array}$ \\
\hline Zj10 & Rovinj, HRV & $N 45^{\circ} 4^{\prime} 38.7^{\prime \prime}$ & $\mathrm{E} 13^{\circ} 40^{\prime} 43.7^{\prime \prime}$ & 'Domaća žižula' \\
\hline Zj11 & Rovinj, HRV & $\mathrm{N} 45^{\circ} 4^{\prime} 39.4^{\prime \prime}$ & $\mathrm{E} 13^{\circ} 40^{\prime} 43.7^{\prime \prime}$ & 'Sitnoplodna' \\
\hline Zj12 & Rovinj, HRV & $\mathrm{N} 45^{\circ} 4^{\prime} 37.3^{\prime \prime}$ & $\mathrm{E} 13^{\circ} 40^{\prime} 42.6^{\prime \prime}$ & 'Domaća žižula' \\
\hline Zj13 & Pobegi, SVN & $\mathrm{N} 45^{\circ} 32^{\prime} 6.41^{\prime \prime}$ & $\mathrm{E} 13^{\circ} 47^{\prime} 20.52^{\prime \prime}$ & 'Domaća žižula' \\
\hline Zj14 & Pobegi, SVN & $\mathrm{N} 45^{\circ} 32^{\prime} 6.41^{\prime \prime}$ & $\mathrm{E} 13^{\circ} 47^{\prime} 20.52^{\prime \prime}$ & 'Lang' \\
\hline Zj15 & Strunjan, SVN & $\mathrm{N} 45^{\circ} 31^{\prime} 16.17^{\prime \prime}$ & $\mathrm{E} 13^{\circ} 37^{\prime} 5.08^{\prime \prime}$ & 'Li' \\
\hline Zj16 & Strunjan, SVN & N45이'37.9" & $\mathrm{E} 13^{\circ} 37^{\prime} 08.0^{\prime \prime}$ & 'Lang' \\
\hline Zj17 & Strunjan, SVN & 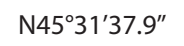 & $\mathrm{E} 13^{\circ} 37^{\prime} 08.0^{\prime \prime}$ & rootstock $^{* *}$ \\
\hline Zj20 & $\begin{array}{l}\text { Nursery Škocjan, Komuna- } \\
\text { la Koper, Ltd., SVN }\end{array}$ & $\mathrm{N} 45^{\circ} 35^{\prime} 12.80^{\prime \prime}$ & $\mathrm{E} 13^{\circ} 73^{\prime} 80.7^{\prime \prime}$ & 'Li' \\
\hline
\end{tabular}

*Samples that were microbiologicaly and chemicaly analysed

**Tree was formed from rootstock after the scion had been detached

\section{Preparation of ethanol and aqueous extracts}

Aqueous and ethanol extracts were prepared according to Yagi et al. (22) for phenolic compound analysis, determination of antioxidant activity, and assessment of antibacterial and antifungal properties. The mesocarp was lyophilized (Alpha 1-2 LDplus; Martin Christ Gefriertrocknungsanlagen $\mathrm{GmbH}$, Osterode am Harz, Germany) and crushed with mortar and pestle to form powder. The aqueous and $70 \%$ ethanol (Sigma-Aldrich, Merck, Steinheim, Germany) mesocarp extracts were prepared using 5 $\mathrm{g}$ of lyophilized material, dissolved in a solvent for $4 \mathrm{~h}$, followed by centrifugation and drying of samples in rotary evaporator at 3000 rpm (HT-4 Series II; Genevac Ltd, Ipswich, UK), lyophilisation (Alpha 1-2 LDplus; Martin Christ Gefriertrocknungsanlagen $\mathrm{GmbH})$, and storage at $-20^{\circ} \mathrm{C}$ until further analysis.

\section{Genetic analysis}

\section{DNA isolation and genotyping}

Total genomic DNA was isolated from young jujube leaves using a modified method by Heidari Japelaghi et al. (23) suitable for plant tissues with high mass fractions of phenolic compounds and polysaccharides. The DNA isolation protocol was modified in the same manner as previously reported for pomegranate (24). DNA concentrations were measured with QubitTM fluorometer (Invitrogen, Thermo Fisher Scientific, Waltham, MA, USA).

Fourteen simple sequence repeat (SSR) loci were selected for jujube DNA genotyping (13,25): Zma-87, Zma-154, Zma-182, Zma-189, BFU0574, BFU1157, BFU0581, BFU0377, BFU0561,
BFU0308, BFU0467, BFU2042, BFU2055 and BFU2077). The 15 $\mu \mathrm{L}$ reaction volume contained $1 \times$ supplied polymerase chain reaction (PCR) buffer (Promega, Manheim, Germany), $2 \mathrm{mM} \mathrm{MgCl}_{2}$ (Promega), $1 \mathrm{mM}$ deoxynucleotide triphosphate (dNTP) solution mix (Sigma-Aldrich, Merck, St. Louis, MO, USA), $0.2 \mu \mathrm{M}$ of forward and reverse primers (IDT-DNA, Leuven, Belgium) where one of the primers was elongated with the M13(-22) tail at the $5^{\prime}$ end (26), $0.25 \mu \mathrm{M}$ of M13 (-22) universal primer labelled with the G5 fluorescent dye set (Applied Biosystems, Woolston, UK), 1.25 unit of Taq (thermostable DNA) polymerase (Promega), and 40 ng of jujube DNA. Microsatellite amplification was performed in a Thermal Cycler 2720 (Applied Biosystems, Thermo Fisher Scientific, Singapore). Microsatellites of the Zma series were amplified with the two-step PCR: in the first step, temperature was set at $94^{\circ} \mathrm{C}$ for $5 \mathrm{~min}$, followed by 5 cycles at $94^{\circ} \mathrm{C}$ for $45 \mathrm{~s}, 30 \mathrm{~s}$ at the initial annealing temperature of $57^{\circ} \mathrm{C}$, which was lowered by $1{ }^{\circ} \mathrm{C}$ in each cycle, and the extension at $72^{\circ} \mathrm{C}$ for $1.5 \mathrm{~min}$. The second step of amplification passed through 30 cycles of $30 \mathrm{~s}$ at $94{ }^{\circ} \mathrm{C}, 30 \mathrm{~s}$ at the initial annealing temperature of $52{ }^{\circ} \mathrm{C}$, and 1.5 min elongation at $72^{\circ} \mathrm{C}$, followed by a final extension step of $10 \mathrm{~min}$ at $72^{\circ} \mathrm{C}$. The microsatellite loci of BFU series were amplified according to the original protocol reported by Schuelke (26). PCR products were separated on automatic 3130 Genetic Analyzer (Applied Biosystems, Hitachi High-Technologies Corporation, Tokyo, Japan). GeneScan ${ }^{\mathrm{TM}} 500$ LIZ $^{\circledR}$ (Applied Biosystems, Thermo Fisher Scientific, Woolston, UK) was used as a size standard, and the length of amplified PCR products was determined with GeneMapper v. 4.1 software (27). 
Data analysis

Basic measures of genetic diversity of 18 jujube samples were taken. The number of alleles, number of effective alleles, observed heterozygosity $(\mathrm{Ho})$, expected heterozygosity $(\mathrm{He})$ and polymorphic information content (PIC) were determined by CERVUS v. 3.0.7 (28). The probability of sampling of identical genetic material in a population was calculated through estimating the probability of identity (PI) with IDENTITY v. 1.0 programme (29). The Jaccard coefficient and unweighted pair group method with arithmetic mean (UPGMA) method were used for assessing genetic similarities among samples and for construction of the dendrogram using the NTSYS v. 2.02 (30). The Mantel test, integrated in the MXCOMP module, was used to test the goodness-of-fit of the cluster analyses using the correlation coefficient between the similarity matrix and the cophenetic value matrix.

\section{Chemical analysis}

\section{Nutritional properties}

Determination of nutritional properties of jujube mesocarp was performed according to the procedure previously described by Miklavčič Višnjevec et al. (24). Determination of total fat was done by automated Soxhlet extraction after digestion of the samples by hydrochloric acid (Sigma-Aldrich, Merck) hydrolysis, followed by extraction of the fats with petroleum ether (Merck, Steinheim, Germany) on Soxtec ${ }^{\mathrm{TM}} 2050$ automatic system (Foss, Hilleroed, Denmark). After the extraction, fat content was determined by weighing. The procedure for water content determination was described in detail by the AOAC method 950.46 (31). Briefly, water content was determined by weighing the sample prior to and after drying for $5 \mathrm{~h}$ at $105{ }^{\circ} \mathrm{C}$ (Universalschrank U; Memmert $\mathrm{GmbH}+\mathrm{Co}$. KG, Schwabach, Germany). A hand refractometer (Atago, Tokyo, Japan) was used for the determination of soluble solids. Protein content was determined in accordance with the method described by Hach et al. (32), with titration of sample distillates $(0.1 \mathrm{M} \mathrm{HCl}$, Merck) after their digestion with concentrated $\mathrm{H}_{2} \mathrm{SO}_{4}$ (Merck). Digest Automat K-438 was used for sample digestion and Distillation Unit B-324 for the distillation (BÜCHI, Flawil, Switzerland), and 702 SM Titrino titrator for distillate titration (Metrohm, Zofingen, Switzerland). The total, soluble and insoluble fibre were determined with the modified enzymatic-gravimetric method reported by Lee at al. (33) using Total Dietary Fibre kit (Merck). Total fibre was calculated as the sum of soluble and insoluble fibre.

\section{Mineral content}

Mass fractions of phosphorus, sulphur, chlorine, potassium, calcium, manganese, iron, nickel, copper, zinc, selenium, lead, bromide, rubidium, strontium and molybdenum were determined by energy dispersive X-ray fluorescence spectrometry using a $\mathrm{Si}(\mathrm{Li})$ detector (Canberra, Meriden, CT, USA), a spectroscopy amplifier (model M2024; Canberra), an analog-to-digital converter (model M8075; Canberra), and a PC-based multichannel analyzer (model S-100; Canberra). About 0.5 to $1.0 \mathrm{~g}$ of each sample was weighed to prepare the pellets using in-house made pellet die and hydraulic press. The disc radioisotope excitation sources of Fe-55 (925 MBq) and Cd-109 (740 MBqi) were used (Eckert and Ziegler, Valencia, CA, USA) as the primary excitation sources. The AXIL spectral analysis programme (34) was used for the analysis of complex $X$-ray spectra, while the quantification was performed with the quantitative analysis of environmental sample software (QAES) developed in-house (35). The uncertainty of the method was estimated to be relatively high, ranging from 5 to $10 \%$. This was the consequence of the geometry calibration procedures that included the errors of tabulated fundamental parameters, the matrix correction contributions, and spectrum acquisition and analysis contributions. The procedure was described in detail by Nečemer et al. (35).

\section{The composition of fatty acids}

The composition of fatty acids was determined in dry jujube endocarps. The fat in $100 \mathrm{mg}$ dry jujube endocarp samples was extracted by $2 \mathrm{~mL}$ heptane (Sigma-Aldrich, Merck). Transmethylation was followed by $30 \mathrm{~s}$ of shaking by hand with $200 \mu \mathrm{L}$ methanol (Sigma-Aldrich, Merck) and $2 \mathrm{~mol} / \mathrm{L}$ $\mathrm{KOH}$ (Sigma-Aldrich, Merck), and then the samples were left to stratify until the upper solution became clear.

The fraction with fatty acid methyl esters was determined by gas chromatography (model 6890N; Agilent Technologies, Santa Clara, CA, USA) with FID detector and the SP-2560 capillary column (100 m×0.25 mm×0.20 $\mu \mathrm{m}$; Supelco, Sigma-Aldrich, Merck, Bellefonte, PA, USA) and the method was previously described by Miklavčič Višnjevec et al. (24). The limit of detection (LOD) and the limit of quantification (LOQ) of the method for each determined fatty acid are shown in Table 2.

\section{Total phenolic content}

The total phenolic content (TPC) of the jujube fruit samples was determined spectrophotometrically (UV-Visible spectrophotometer 8453; Hewlett Packard, Waldbronn, Germany). TPC was calculated from the calibration curve constructed by using standard solutions of gallic acid and expresed in mg galic acid equivalents (GAE) per $\mathrm{g}$ of dry mass ( $\mathrm{dm}$ ) of sample. All data are the average of triplicate measurements.

\section{Determination of individual phenolic compounds}

The detailed description of the method for individual phenolic compound determination was previously reported by Miklavčič Višnjevec et al. (24). The phenolic compounds were determined by an ultra-high-pressure liquid chromatography system (UHPLC), interfaced with a triple quadrupole mass spectrometer (QqQ MS/MS 6420 system; Agilent Technologies, Singapore, and HPLC 1260 system; Waldbronn, Germany) equipped with standard electrospray ionization source (model G1948B), a degasser (model G4225A), a binary 
Table 2. Fatty acid composition of jujube endocarp from samples Zj2-Zj6

\begin{tabular}{|c|c|c|c|c|c|c|}
\hline \multirow{2}{*}{ Fatty acid } & \multicolumn{3}{|c|}{$w / \%$} & \multirow{2}{*}{$\begin{array}{c}\text { SD } \\
\%\end{array}$} & \multirow{2}{*}{$\begin{array}{c}\text { LOD } \\
\%\end{array}$} & \multirow{2}{*}{$\frac{\text { LOQ }}{\%}$} \\
\hline & Med & Min & Max & & & \\
\hline C $14: 0$ & 0.05 & $<\mathrm{LOD}$ & 0.23 & 0.089 & 0.0001 & 0.001 \\
\hline C $16: 0$ & 5.33 & 4.93 & 6.64 & 0.733 & 0.007 & 0.011 \\
\hline C $16: 1$ & 0.13 & $<\mathrm{LOD}$ & 0.23 & 0.107 & 0.001 & 0.002 \\
\hline C 17:0 & 0.06 & $<$ LOD & 0.08 & 0.037 & 0.001 & 0.002 \\
\hline C $17: 1$ & 0.05 & $<\mathrm{LOD}$ & 0.06 & 0.029 & 0.0001 & 0.001 \\
\hline C 18:0 & 2.85 & 2.26 & 4.29 & 0.756 & 0.006 & 0.009 \\
\hline C $18: 1$ & 33.37 & 32.3 & 36.03 & 1.44 & 0.012 & 0.029 \\
\hline C $18: 2$ & 52.70 & 50.82 & 54.45 & 1.57 & 0.001 & 0.003 \\
\hline C $18: 3$ & 0.71 & 0.52 & 2.18 & 0.686 & 0.001 & 0.002 \\
\hline C 20:0 & 0.58 & 0.42 & 0.73 & 0.125 & 0.0001 & 0.001 \\
\hline C 20:1 & 2.09 & 2.01 & 2.78 & 0.322 & 0.0001 & 0.001 \\
\hline C 22:0 & 0.47 & 0.38 & 0.72 & 0.136 & 0.0001 & 0.001 \\
\hline C 24:0 & 0.24 & 0.17 & 0.33 & 0.061 & 0.0001 & 0.001 \\
\hline trans-C 18:1 & $<$ LOD & $<\mathrm{LOD}$ & 0.015 & 0.007 & 0.0001 & 0.001 \\
\hline trans $-\mathrm{C} 18: 2$ and trans $-\mathrm{C} 18: 3$ & 0.06 & $<$ LOD & 0.104 & 0.047 & 0.001 & 0.001 \\
\hline
\end{tabular}

$\mathrm{SD}=$ standard deviation, $\mathrm{LOD}=$ limit of detection, $\mathrm{LOQ}=$ limit of quantification

gradient pump (model G1312A), a thermoautosampler (model G1329B), a column oven (model G1316A), a diode array detection system (model G4212B), a Poroshell 120 column (EC-C18; $2.7 \mu \mathrm{m} ; 3.0 \mathrm{~mm} \times 50 \mathrm{~mm}$ ) and MassHunter qualitative/quantitative analysis software B.05.00 (36). The elution gradient of water/formic acid (99.5:0.5, V/V) (A) and acetonitrile/methanol $(50: 50, V / V)$ (B) was the same as used in the previous study (24). The catechin, epicatechin and gallic acid standards (Sigma-Aldrich, Merck) and delphinidin-3,5-di-O-glucoside, cyanidin-3,5-di-O-glucoside and pelargonidin-3,5-di-O-glucoside standards (Extrasynthese, Genay, France) were used to optimize the method conditions. The main parameters regarding ionization and fragmentation were optimized by each standard solution using both positive and negative ionization mode. Positive ion modes provided better sensitivity for the determination of anthocyanins, while negative ion modes provided better sensitivity for all the other determined compounds. Collision energies and fragmentor voltage were adjusted in order to optimize the signal for the most abundant ions for each standard solution. The MS and MS/MS spectra were acquired using the following optimized conditions: collision energy (15-45 eV), cell acceleration voltage (7 $\mathrm{V})$, fragmentor voltage $(80-220 \mathrm{~V})$, capillary voltage $(4.0 \mathrm{kV})$ and sheath gas temperature $\left(300^{\circ} \mathrm{C}\right)$, flow $(11 \mathrm{~L} / \mathrm{min})$ and pressure (241.32 kPa). The level of each phenolic compound was calculated on the basis of the constructed calibration curves ( $y=33.097 x$ for catechin, $y=351.83 x$ for epicatechin, $y=862.67 x$ for gallic acid, $y=46 x+37.5$ for delphinidin-3,5-di-O-glucoside, $y=60 x+37.5$ for cyanidin-3,5-di-O-glucoside and $y=79 x+50$ for pelargonidin-3,5-di-O-glucoside). The $\mathrm{R}^{2}$ of the calibration curves ranged from 0.986 to 0.999 . In addition, delphinidin-3,5-di-O-glucoside, cyanidin-3,5-di-O-glucoside and pelargonidin-3,5-di-O-glucoside mass fractions were calculated using their respective chlorides. The solution of syringic acid (Sigma-Aldrich, Merck) was added to the calibration standards and samples as internal standard. The LOD of the method was $0.002 \mathrm{mg} / 100 \mathrm{~g}$ sample for delphinidin-3,5-di-O-glucoside, pelargonidin-3,5-di-O-glucoside, cyanidin-3,5-di-O-glucoside and gallic acid, and $0.01 \mathrm{mg} / 100 \mathrm{~g}$ sample for epicatechin and catechin. All data are the average of duplicate measurements.

\section{Antioxidant activity}

The method for the spectrophotometric determination of the antioxidant activity by 2,2-diphenyl-1-picryl-hydrazyl (DPPH; Sigma-Aldrich, Merck) of the aqueous and ethanol extracts of the jujube fruit is described by Miklavčič Višnjevec et al. (24). Extracts were added to DPPH' solution and absorbance at $517 \mathrm{~nm}$ was measured after $30 \mathrm{~min}$ (UV-Vis spectrophotometer 8453; Hewlett Packard). All data are the average of triplicate measurements.

\section{Microbiological analysis}

\section{Antibacterial activity}

The procedure for the determination of the antibacterial activity was described recently by Miklavčič Višnjevec et al. (24). The aqueous and ethanol extracts of the jujube mesocarp were tested against the following clinical isolates: Staphylococcus aureus (ATCC 25923), Listeria monocytogenes (ŽMJ58a), Escherichia coli (O157:H7 ŽMJ370) and Pseudomonas aeruginosa (ŽMJ87). Mueller-Hinton agar or broth (Oxoid, Hampshire, UK) were used as the cultivation assay media. The microdilution method was used for the determination of the minimum inhibitory concentrations (MICs) of the samples as previously described (37). The 2-p-iodophenyl-3-p-nitrophenyl-5-phenyl tetrazolium chloride (Sigma-Aldrich, Merck), which produces a red formazan dye upon reduction, was used to determine the presence of colour for the assessment of the respiratory activity. All data are the average of duplicate measurements. 
Antifungal activity

Determination of the antifungal activity of aqueous and ethanol extracts followed the procedure of the reference methods for broth dilution antifungal susceptibility testing of yeast (M27-A3) (38) and filamentous fungi (M38-A2) (39). The aqueous and ethanol extracts of jujube mesocarp were tested against Exophiala dermatitidis (EXE 5586), Saprochaete clavata (EXE 5631), Rhodotorula mucilaginosa (EXE 9762), Candida albicans (EXE 9382), Aspergillus fumigatus (EXE 8280), Candida parapsilosis (EXE 9370), Fusarium dimerum (EXE 9214) and Aureobasidium pullulans (EXE 3105). All data are the average of duplicate measurements of growth in RPMI medium.

\section{Statistical analysis}

Stata v. 13 software (40) was used for statistical analysis of the chemical data. The distribution of the TPC and antioxidant activity are shown as a box plot. Shapiro-Wilk test was used to assess the normality of the analysed chemical data. The correlations were determined by the Spearman's rank coefficients, and non-parametric test (Wilcoxon-Mann-Whitney) was used for comparison of the two different groups. The level for statistical significance was set to $\mathrm{p}<0.05$.

\section{RESULTS AND DISCUSSION}

\section{Genetic characteristics of jujube}

Fourteen highly polymorphic microsatellite loci were chosen for genotyping of jujube germplasm from Istrian peninsula. All parameters of genetic variability of simple sequence repeat (SSR) loci obtained among 18 jujube samples are presented in Table 3. Microsatellites were successfully amplified in all examined jujubes, and a total of 51 different alleles were detected. The number of amplified alleles at each locus ranged from three to five, with a mean of 3.6 alleles per locus, and on average, 1.95 effective alleles per locus were detected. The observed and expected heterozygosity varied from 0.111 (Zma-189) to 1.000 (BFU2042) and 0.338 (Zma-182, BFU2055) to 0.694 (BFU2042), respectively. The polymorphic information content (PIC) value ranged from 0.300 (Zma-182 and BFU2055) to 0.613 (Zma-87), with a mean value of 0.415 . Based on the calculated PIC, only four SSR loci (Zma-87, BFU0308, BFU0467 and BFU2042) were classified as highly informative markers (PIC>0.5) (41). Values of probability of identity $(\mathrm{PI})$ varied among loci in a range from 0.285 (Zma-87) to 0.538 (Zma-182 and BFU2055), and the PI value for all loci was 5.19·10-6. In most cases (except loci Zma87, BFU0308, BFU0467 and BFU2042) PI values were high, indicating that SSR loci yielded low discriminating capacity. All genetic parameters obtained using these 14 microsatellite loci were significantly lower than those obtained in previous studies $(13,15)$, most likely due to the relatively small jujube sample size used in our study. Among the 18 analysed jujube samples, only five different jujube genotypes were detected, while in other studies the number of analysed jujube varieties/accessions ranged from $76(13)$ to 150 (14), and even $962(10)$.

The genetic relationships among the 18 jujube samples are presented in the dendrogram generated by Jaccard's similarity matrix using the unweighted pair group method with arithmetic mean (UPGMA) method (Fig. 1). The cophenetic correlation coefficient was 0.998 , indicating that the dendrogram was significantly correlated with the similarity matrix from which it was computed.

The cluster analysis of the jujube samples indicated two major clusters. The first cluster consisted of jujube samples with local names 'Navadna žižola' (SVN), 'Domaća žižula' (HRV), and 'Sitnoplodna' (HRV), which have smaller fruits. All these samples, except Zj11, have an identical genetic profile, confirming synonymy of 'Navadna žižola' (Slovenian meaning common jujube) and 'Domaća žižula' (Croatian meaning domestic jujube). This result indicated that these samples were

Table 3. Parameters of genetic variability of simple sequence repeat (SSR) loci obtained among jujube samples that were included in this study

\begin{tabular}{|c|c|c|c|c|c|c|}
\hline \multirow{2}{*}{ Locus } & \multicolumn{2}{|c|}{ Allele } & \multicolumn{2}{|c|}{ Heterozygosity } & \multirow{2}{*}{$\mathrm{PIC}$} & \multirow{2}{*}{$\mathrm{PI}$} \\
\hline & Number detected & Effective number & Observed & Expected & & \\
\hline Zma-87 & 4 & 3.057 & 0.778 & 0.692 & 0.613 & 0.285875 \\
\hline Zma-154 & 3 & 1.766 & 0.389 & 0.446 & 0.386 & 0.462397 \\
\hline Zma-182 & 3 & 1.490 & 0.389 & 0.338 & 0.300 & 0.538119 \\
\hline Zma-189 & 3 & 1.906 & 0.111 & 0.489 & 0.404 & 0.490722 \\
\hline BFU0574 & 3 & 1.588 & 0.444 & 0.381 & 0.340 & 0.486968 \\
\hline BFU1157 & 4 & 1.503 & 0.389 & 0.344 & 0.314 & 0.505779 \\
\hline BFU0581 & 3 & 1.588 & 0.444 & 0.381 & 0.340 & 0.486968 \\
\hline BFU0377 & 4 & 1.592 & 0.389 & 0.383 & 0.344 & 0.478973 \\
\hline BFU0561 & 3 & 1.573 & 0.333 & 0.375 & 0.327 & 0.516785 \\
\hline BFU0308 & 5 & 2.374 & 0.389 & 0.595 & 0.542 & 0.288634 \\
\hline BFU0467 & 5 & 2.356 & 0.389 & 0.592 & 0.536 & 0.298531 \\
\hline BFU2042 & 4 & 3.071 & 1.000 & 0.694 & 0.612 & 0.292330 \\
\hline BFU2055 & 3 & 1.490 & 0.389 & 0.338 & 0.300 & 0.538119 \\
\hline BFU2077 & 4 & 1.934 & 0.389 & 0.497 & 0.449 & 0.369748 \\
\hline Cumulative & 51 & n.c. & n.c. & n.c. & n.c. & $5.19 \cdot 10^{-6}$ \\
\hline
\end{tabular}

$\mathrm{PIC}=$ polymorphic information content, $\mathrm{Pl}=$ probability of identity, n.c.=not calculated 


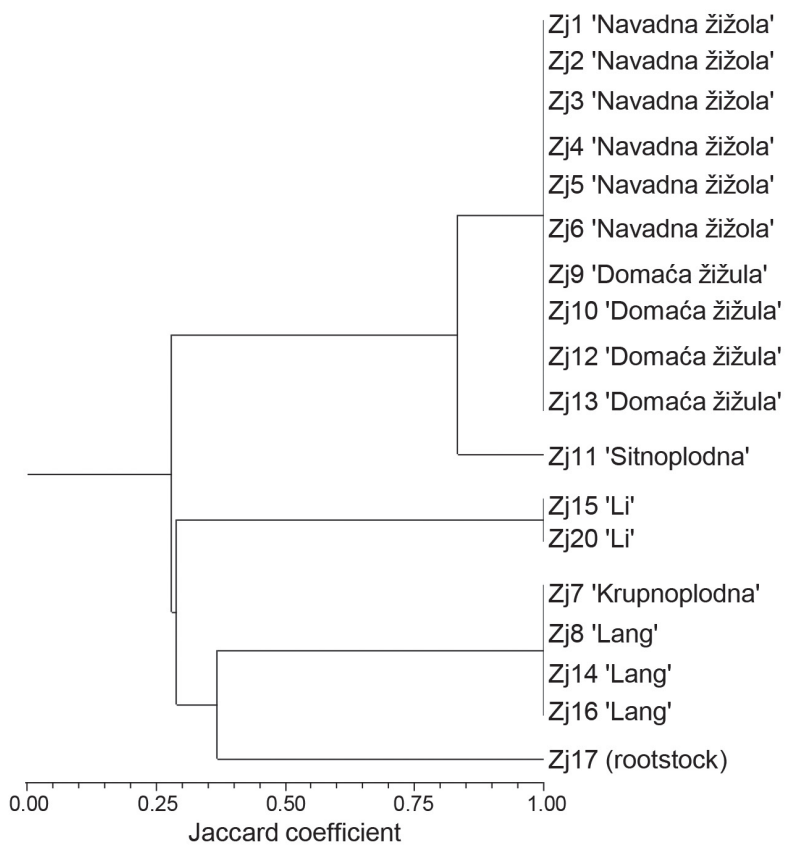

Fig. 1. Dendrogram of the 18 jujube samples from Slovenian and Croatian Istrian peninsula based on the unweighted pair group method with arithmetic mean (UPGMA) and the Jaccard similarity coefficients. Dendrogram was constructed with NTSYS v. 2.02 (30)

probably vegetatively propagated trees derived from similar or identical genetic material. Since the origin of the local variety 'Navadna žižola' (SVN)/'Domaća žižula' (HRV) is not known, additional genetic analyses are necessary to identify potential synonyms or genetic similarities with other known varieties. Fruits and leaves characteristic to 'Navadna žižola', which is the most widespread in the Slovenian part of Istria peninsula, are shown in supplementary material (Fig. S1 and Fig. S2). The oldest tree from Slovenia included in the analysis was 130 years old (sample Zj5) and from Croatia 50 years old (Zj9), indicating a relatively long presence of jujubes in Slovenia and Croatia. Molecular analysis demonstrated the uniqueness of the genetic profile of sample Zj11 (Croatian 'Sitnoplodna' meaning thin-fruited), suggesting further agronomic and nutritional evaluation for determination of its potential.

The second cluster included jujube varieties 'Li' and 'Lang' with a thick and fleshy mesocarp, as well as sample Zj17 (Fig. 1). Based on literature data $(42,43)$, jujube varieties 'Li' and 'Lang' were chosen as recommended varieties, 'Li' as the most suitable for eating fresh and 'Lang' for dried food and for processing. Sample Zj17 is a small tree, producing thin sour fruits, and was formed from the rootstock after the scion had been detached (personal communication, V. Knez). According to literature (9), the sour jujube (Z. acidojujuba C.Y. Cheng and M.J. Liu, synonym Z. jujuba var. spinosa $\mathrm{Hu}$ ), which is believed to be the wild form of jujube, represents the most popular rootstock due to their availability and stress tolerance. However, since seedlings and root suckers are also used for rootstock, the identity of the sample Zj17 was not determined.

\section{Chemical properties of jujube fruit}

Protein, total lipid, ash, fibre and mineral content were determined in jujube fruit grown in Istria (Table 4). Results confirmed that the jujube fruit is a good source of dietary fibre which may contribute to regulation of blood sugar levels by slowing the digestion and controlling calorie intake by its satiating effect (44). Interestingly, the latest studies have shown that polysaccharides isolated from Z. jujuba with different extraction and purification methods have various physiochemical properties and bioactivities such as immunomodularity, antioxidant, antitumour, hepatoprotective and gastrointestinal protective effects (8). Li et al. (45) reported similar levels of insoluble dietary fibre in the samples of Zizyphus jujuba varieties 'Jinsixiaozao', 'Jianzao', 'Yazao', 'Junzao' and 'Sanbianhong' to the levels in jujube fruit from Istrian peninsula obtained in our study, whereas the mass fractions of the soluble dietary fibre were higher in our study. These results indicate that the genotype might be important factor for the fibre determination. In addition, jujube fruit is a rich source of minerals such as potassium, calcium, phosphorus and zinc, as it was observed in our study (Table 4). Similar observations have been reported in the literature $(9,43,46)$. Our study showed higher mass fractions (in mg per $100 \mathrm{~g} \mathrm{dm}$ ) of calcium $(177 \pm 11)$, iron $(6.5 \pm 0.9)$ and zinc $(0.9 \pm 0.2)$ than the data from USDA National Nutrient Database: 94, 2.12 and 0.22, respectively (43). The observed differences can be attributed to the different geographical position, ecological factors, soil characteristics, and genotype. More data is needed to confirm these observations.

Table 4. Mass fractions of proteins, total lipid, ash, fibre (on wet mass basis), and minerals (on dry mass basis) of jujube sample Zj2

\begin{tabular}{cc} 
Component & $w /(\mathrm{g} / 100 \mathrm{~g})$ \\
Protein & $0.6 \pm 0.2$ \\
Total lipid & $2.5 \pm 0.2$ \\
Ash & $0.97 \pm 0.01$ \\
Total dietary fibre & $9.7 \pm 0.6$ \\
Insoluble dietary fibre & $6.0 \pm 0.2$ \\
soluble dietary fibre & $3.8 \pm 0.4$ \\
Mineral & $w /(\mathrm{mg} / 100 \mathrm{~g})$ \\
$\mathrm{P}$ & $129 \pm 19$ \\
$\mathrm{~S}$ & $22.8 \pm 6.5$ \\
$\mathrm{Cl}$ & $81 \pm 7$ \\
$\mathrm{~K}$ & $829 \pm 51$ \\
$\mathrm{Ca}$ & $177 \pm 11$ \\
$\mathrm{Mn}$ & $2.0 \pm 0.7$ \\
$\mathrm{Fe}$ & $6.5 \pm 0.9$ \\
$\mathrm{Ni}$ & $0.9 \pm 0.3$ \\
$\mathrm{Cu}$ & $1.8 \pm 0.2$ \\
$\mathrm{Zn}$ & $0.9 \pm 0.2$ \\
$\mathrm{Se}$ & $0.2 \pm 0.0$ \\
$\mathrm{~Pb}$ & $0.8 \pm 0.2$ \\
$\mathrm{Br}$ & $0.21 \pm 0.09$ \\
$\mathrm{Rb}$ & $1.1 \pm 0.2$ \\
$\mathrm{Sr}$ & $0.57 \pm 0.08$ \\
$\mathrm{Mo}$ & $0.1 \pm 0.0$ \\
$\mathrm{Cr}$ & 0 \\
\hline
\end{tabular}

Results are expressed as mean values \pm standard deviation. ${ }^{*}$ The total lipid content was determined in jujube endocarp 
Sixteen different fatty acids were determined in the jujube endocarps (Table 3). The predominant fatty acids in all samples were unsaturated fatty acids linoleic (C18:2) and oleic (C18:1) acid that amount to 52.70 and $33.37 \%$ (median levels), respectively. Linoleic acid (omega- 6 ) belongs to essential fatty acids, since the human body is not able to produce it. The data obtained in our study are in accordance with the data reported by Zhao et al. (47), while in addition to the predominant linoleic and oleic fatty acid, San and Yildirim (48) found higher amounts of palmitic and palmitoleic fatty acids. Moreover, they reported significant differences in the amount of each individual fatty acid of jujube fruit among the four jujube genotypes. These differences between studies might be assigned to the different analysed genotypes, as was suggested by San and Yildirim (48) and to different ecological factors, characteristic for a define region.

The TPC was analysed in ethanol and aqueous extracts of the following jujube fruit samples Zj1, Zj2, Zj3, Zj4, Zj5 and Zj6 with the Folin-Ciocalteu reagent (Fig. 2). Although the extraction method for the determination of phenolic compounds was different in the study of Li et al. (45), and the reported levels of TPC (as GAE) ranged from 5.2 to $8.5 \mathrm{mg} / \mathrm{g}$ in fruits of various Zizyphus jujuba varieties, these values were comparable to the data obtained in our study. The determined mass fractions (in mg GAE per g) were significantly higher in ethanol extracts (Med=7.5, Min=5.8, Max=8.7) than in the aqueous extracts ( $M e d=3.3, M i n=2.4, M a x=4.6$ ). These results are the consequence of the prevalence of phenolic compounds in jujube fruit that are more soluble in polar organic solvents such as ethanol than in the aqueous medium. There were no major differences in the TPC observed among the samples with identical

a)

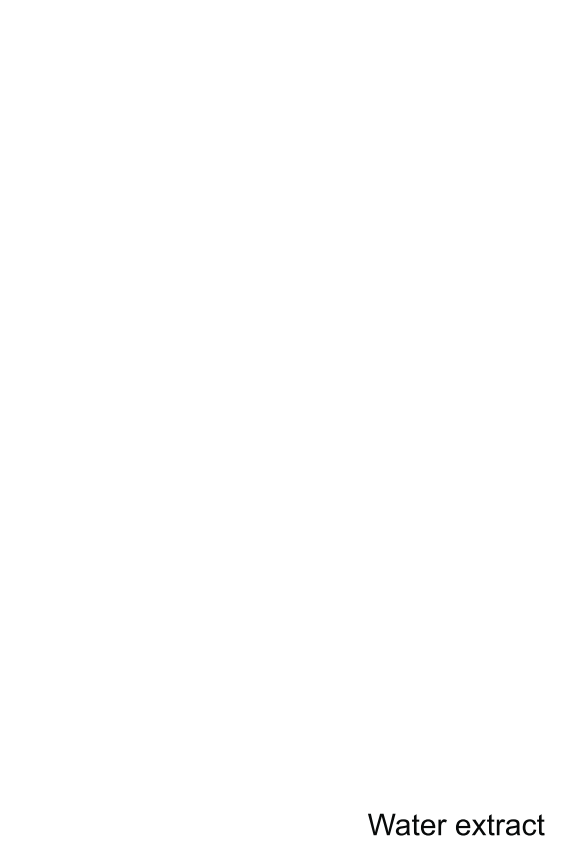

genetic profile, grown in different locations on Slovenian Istrian peninsula (Fig. 1). In addition, epicatechin, catechin, gallic acid, delphinidin-3,5-di-O-glucoside, cyanidin-3,5-di-O-glucoside and pelargonidin-3,5-di-O-glucoside were determined in ethanol and aqueous mesocarp extracts of the same samples (Fig. 3). As in the case of TPC, higher mass fractions of phenolic compounds were determined in the ethanol extracts than in the aqueous extracts (Fig. 3). Epicatechin (Med=0.10 mg/100 g, Min $<L O D, M a x=0.39 \mathrm{mg} / 100 \mathrm{~g}$ ) was the predominant phenolic compound determined in this study. However, contrary to the determined mass fractions of the TPC, differences in the TPC of various samples were observed, which might be attributed to the different environmental factors, or to minor differences of the maturity stage of the fruit.

The phenolic compounds have the ability to scavenge free radicals, superoxide and hydroxyl radicals by single-electron transfer. Therefore, in some fruits the antioxidant capacity is directly correlated with the amount of phenolic compounds $(24,49,50)$. As it was determined for the TPC (Fig. 2) and individual phenolic compounds (Fig. 3), the ethanol extracts had higher antioxidant potential (in mg GAE per g): $\mathrm{Med}=0.40$, Min $=0.28$, Max $=0.50$ ) than the aqueous extracts ( $M e d=0.18$, Min=0.14, Max=0.27) (Fig. 2). However, the antioxidant potential was not proportional to the content of TPC. These results are in accordance with the studies of Li et al. (45) and Ji et al. (8) where no correlation between the TPC and the antioxidant potential was found. This result might be explained with the presence of other compounds such as polysaccharides, vitamin $C$ and pigments in jujube fruits $(8,19)$ that have the antioxidant potential, or due to the synergistic antioxidant effects among them.

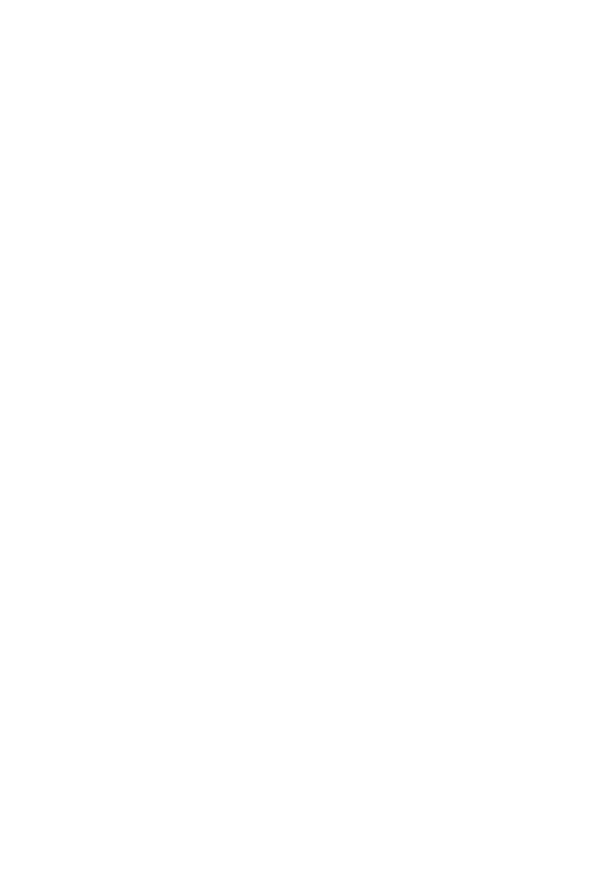

Fig. 2. Determination of: a) total phenolic content (TPC) and b) antioxidant potential of aqueous and ethanol extract of jujube mesocarp. Results are based on the samples from $\mathrm{Zj} 1$ to $\mathrm{Zj} 6$. GAE=gallic acid equivalents 


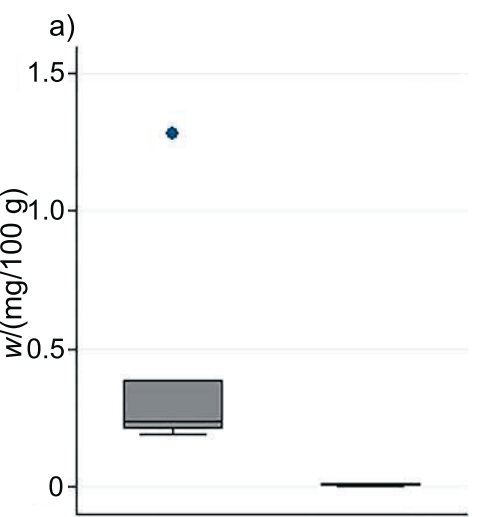

d)

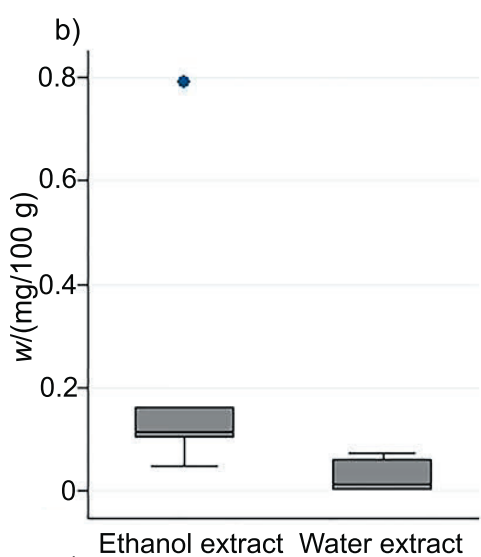

e)

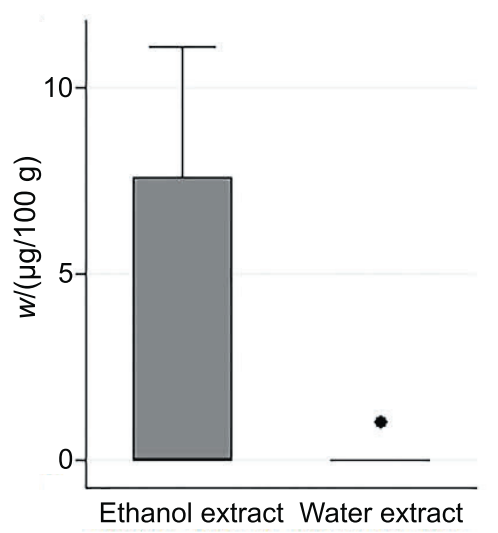

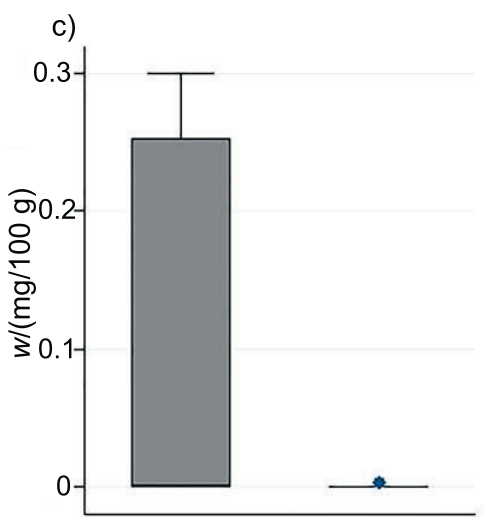

f)

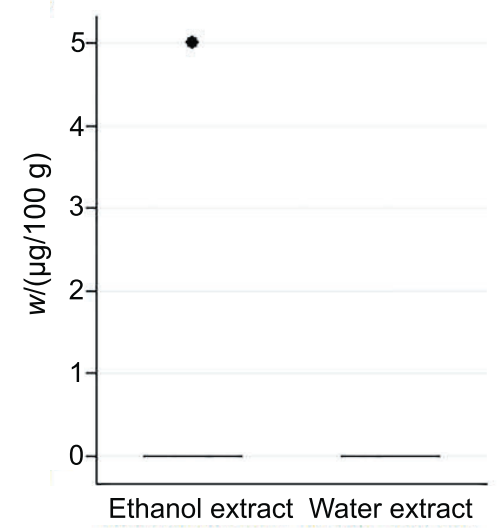

Fig. 3. Phenolic compounds: a) epicatechin, b) catechin, c) gallic acid, d) delphinidin-3,5-di-O-glucoside, e) cyanidin-3,5-di-O-glucoside and f) pelargonidin-3,5-di-O-glucoside determined in ethanol and aqueous extracts obtained from mesocarp of jujube. Results are based on the samples from Zj1 to Zj6

Table 5. Antibacterial activity in different samples of aqueous extracts of jujube mesocarp

\begin{tabular}{|c|c|c|c|c|c|c|c|}
\hline \multirow{2}{*}{ Bacterium } & \multirow{2}{*}{ Control } & \multicolumn{6}{|c|}{$\mathrm{MIC} /(\mathrm{mg} / \mathrm{mL})$} \\
\hline & & Zj1 & $\mathrm{Zj} 2$ & Zj3 & Zj4 & Zj5 & Zj6 \\
\hline Escherichia coli ŽM370 & ND & 2.5 & 5 & 2.5 & 5 & 2.5 & 5 \\
\hline Listeria monocytogenes ŽMJ58a & ND & 10 & ND & 10 & ND & ND & ND \\
\hline Pseudomonas aeruginosa ŽMJ87 & ND & ND & ND & ND & ND & ND & ND \\
\hline Staphylococcus aureus ŽMJ72 & ND & 1.25 & 2.5 & 1.25 & 2.5 & 2.5 & 2.5 \\
\hline
\end{tabular}

$\mathrm{MIC}=$ minimum inhibitory concentration, $\mathrm{ND}=$ antibacterial activity not detected

\section{Antibacterial and antifungal activity of jujube fruit}

The tests for antibacterial and antifungal activity did not demonstrate antimicrobial activity of the jujube ethanol extracts of the selected samples (Zj1, Zj2, Zj3, Zj4, Zj5 and Zj6) for which the antioxidant activity and the mass fractions phenolic compounds and antioxidative potential were determined. The results obtained in our study suggest that of phenolic compounds found in ethanol extracts of jujube mesocarp are not involved in the antibacterial and antifungal activity of the samples. However, the aqueous extracts of jujube mesocarp showed slight antibacterial activity against Escherichia coli and Staphylococcus aureus (Table 5), but antifungal activity has not been confirmed. More data is needed to confirm these observations.

\section{CONCLUSIONS}

Genetic analysis revealed the existence of five different jujube genotypes in the region of the Istrian peninsula. Local varieties named 'Navadna žižola' (SVN) and 'Domaća žižula' (HRV) shared an identical genetic profile, indicating that the same genetic material is spread in the Slovenian and Croatian part of Istria. We therefore confirmed that 'Navadna žižola' and 'Domaća žižula' are synonyms. The first results of our study show that samples of 'Navadna žižola' (SVN) from Istrian peninsula are a valuable source of dietary fibre. The measured mass fractions were higher than those found in some other varieties reported in the literature. Moreover, our study confirmed that jujube fruit is rich in minerals. According to the results, the fruits of 'Navadna žižola' contained higher mass fractions of calcium, 
iron and zinc than those in jujube fruit reported in the USDA data. However, further studies will be necessary to confirm these observations. Phenolic compounds determined in the extracts of the selected samples were not directly correlated with antioxidant activity, which is likely due to the synergistic effect of other antioxidants such as polysaccharides and vita$\min C$. In contrast to the aqueous extracts that showed slight antibacterial activity, ethanol extracts, which contained significantly higher mass fractions of phenolic compounds than those found in aqueous extracts, did not demonstrate antimicrobial activity. Our study suggests that other compounds than the phenolics in jujube fruit might be more biologically active. Based on our assessment of the described characteristics, the main hypothesis of this study was confirmed. The local variety 'Navadna žižola' (SVN)/'Domaća žižula' (HRV) grown on the Istrian peninsula has promising cultivation potential displaying beneficial nutritional and antimicrobial properties.

\section{ACKNOWLEDGEMENTS}

This research was part of the project 'The Vegetation of Istria: Preservation of natural heritage - the revitalization of fruit species characteristic for the area of Istria' that included the investigation of different horticultural and some ornamental plants. The authors thank Prof. Dr Sonja Smole-Možina and Prof. Dr Nina Gunde-Cimerman for using their laboratory facilities for performing microbiological analyses. The authors are very grateful to Dr Peter Kump for kindly providing the Quantitative Analysis of Environmental Samples (QAES) software. Also, the authors thank Dr Željko Prgomet, CEO of Nursery Skink Ltd. from Rovinj, for providing us with jujube samples.

\section{FUNDING}

This study was funded by European Regional Development Funds (Rast Istre, SI-HR-3-2-001), the Slovenian Research Agency, and the Slovenian Government Office for Development and European Cohesion Policy.

\section{SUPPLEMENTARY MATERIAL}

All supplementary material is available at www.ftb.com.hr.

\section{REFERENCES}

1. Vijayan K, Chakraborti SP, Ercisli S, Ghosh PD. NaCl induced morpho-biochemical and anatomical changes in mulberry (Morus spp.). Plant Growth Regul. 2008;56:61-9. https://doi.org/10.1007/s10725-008-9284-5

2. Ercisli S, Tosun M, Karlidag H, Dzubur A, Hadziabulic S, Aliman Y. Color and antioxidant characteristics of some fresh fig (Ficus carica L.) genotypes from Northeastern Turkey. Plant Food Hum Nutr. 2012;67(3):271-6. https://doi.org/10.1007/s11130-012-0292-2

3. Cüce $M$, Sökmen A. In vitro production protocol of Vaccinium uliginosum L. (bog bilberry) growing in the Turkish flora. Turk J Agric For. 2017;41:294-304.

https://doi.org/10.3906/tar-1704-19

4. Huang J, Yang X, Zhang C, Yin X, Liu S, Li X. Development of chloroplast microsatellite markers and analysis of chloroplast diversity in Chinese jujube (Ziziphus jujuba Mill.) and wild jujube (Ziziphus acidojujuba Mill.). PLoS ONE. 2015;10(9):e0134519.

https://doi.org/10.1371/journal.pone.0134519

5. Liu MJ, Liu P, Liu GN. Advances of research on germplasm resources of Chinese jujube. Acta Hortic. 2013;993:15-20. https://doi.org/10.17660/ActaHortic.2013.993.1

6. Chen J, Liu X, Li Z, Qi A, Yao P, Zhou Z, et al. A review of dietary Ziziphus jujuba fruit (jujube): Developing health food supplements for brain protection. Evid-Based Compl Alt. 2017;2017:3019568.

https://doi.org/10.1155/2017/3019568

7. Preeti KM, Tripathi S. Ziziphus jujuba: A phytopharmacological review. Int J Res Dev Pharm L Sci. 2014;3(3):959-66.

8. Ji X, Peng Q, Yuan Y, Shen J, Xie X, Wang M. Isolation, structures and bioactivities of the polysaccharides from jujube fruit (Ziziphus jujuba Mill.): A review. Food Chem. 2017;227:349-57.

https://doi.org/10.1016/j.foodchem.2017.01.074

9. Liu M, Zhao Z. Origin, distribution, germplasm, and growing of Chinese dates. In: Liu D, Ye X, Jiang Y, editors. Chinese date: A traditional functional food. Boca Raton, FL, USA: CRC Press; 2016. pp. 23-31.

https://doi.org/10.1201/b20025

10. Xu C, Gao J, Du Z, Li D, Wang Z, Li Y, Pang X. Identifying the genetic diversity, genetic structure and a core collection of Ziziphus jujuba Mill. var. jujuba accessions using microsatellite markers. Sci Rep-UK. 2016;6:Article no. 31503.

https://doi.org/10.1038/srep31503

11. Kalia RK, Rai MK, Kalia S, Singh R, Dhawan AK. Microsatellite markers: an overview of the recent progress in plants. Euphytica. 2011;177(3):309-34.

https://doi.org/10.1007/s10681-010-0286-9

12. Ma QH, Wang GX, Liang LS. Development and characterization of SSR markers in Chinese jujube (Ziziphus jujuba Mill.) and its related species. Sci Hortic. 2011;129(4):597-602. https://doi.org/10.1016/j.scienta.2011.04.032

13. Wang SQ, Liu Y, Ma L, Liu H, Tang Y, Wu L, et al. Isolation and characterization of microsatellite markers and analysis of genetic diversity in Chinese jujube (Ziziphus jujuba Mill.). PLoS ONE. 2014;9:e99842.

https://doi.org/10.1371/journal.pone.0099842

14. Chen W, Hou L, Zhang Z, Pang X, Li Y. Genetic diversity, population structure, and linkage disequilibrium of a core collection of Ziziphus jujuba assessed with genome-wide SNPs developed by genotyping by sequencing and SSR Markers. Front Plant Sci. 2017;8:Article no. 575.

https://doi.org/10.3389/fpls.2017.00575 
15. Liu MJ, Zhao J, Cai QL, Liu GC, Wang JR, Zhao ZH, et al. The complex jujube genome provides insights into fruit tree biology. Nat Commun. 2014;5(1):5315.

https://doi.org/10.1038/ncomms6315

16. Huang J, Zhang C, Zhao X, Fei Z, Wan K, Zhang Z, et al. The jujube genome provides insights into genome evolution and the domestication of sweetness/acidity taste in fruit trees. PLoS Genet. 2016;12(12):e1006433. https://doi.org/10.1371/journal.pgen.1006433

17. Zhang Z, Wei T, Zhong Y, Li X, Huang J. Construction of a high-density genetic map of Ziziphus jujuba Mill. using genotyping by sequencing technology. Tree Genet Genomes. 2016;12:Article no. 76.

https://doi.org/10.1007/s11295-016-1032-9

18. Ahmad M, Qureshi R, Arshad M, Khan MA, Zafar M. Traditional herbal remedies used for the treatment of diabetes from district Attock (Pakistan). Pak J Bot. 2009;41(6):2777-82.

19. Pareek S. Nutritional composition of jujube fruit. Emir J Food Agric. 2013;25(6):463-70.

https://doi.org/10.9755/ejfa.v25i6.15552

20. Bai L, Zhang H, Liu Q, Zhao Y, Cui X, Guo S, et al. Chemical characterization of the main bioactive constituents from fruits of Ziziphus jujuba. Food Funct. 2016;7(6):2870-7. https://doi.org/10.1039/c6fo00613b

21. Lancaster JE, Reay PF, Norris J, Butler RC. Induction of flavonoids and phenolic acids in apple by UV-B and temperature. J Hortic Sci Biotechnol. 2000;75(2):142-8.

https://doi.org/10.1080/14620316.2000.11511213

22. Yagi S, Chrétien F, Duval RE, Fontanay S, Maldini M, Piacente $S$, et al. Antibacterial activity, cytotoxicity and chemical constituents of Hydnora johannis roots. S Afr J Bot. 2012;78:228-34.

https://doi.org/10.1016/j.sajb.2011.09.010

23. Heidari Japelaghi R, Haddad R, Garoosi GA. Rapid and efficient isolation of high quality nucleic acids from plant tissues rich in polyphenols and polysaccharides. Mol Biotechnol. 2011;49(2):129-37.

https://doi.og/10.1007/s12033-011-9384-8

24. Miklavčič Višnjevec A, Ota A, Skrt M, Butinar B, Smole Možina S, Gunde Cimerman N, et al. Genetic, biochemical, nutritional and antimicrobial characteristics of pomegranate (Punica granatum L.) grown in Istria. Food Technol Biotechnol. 2017;55(2):151-63.

https://doi.org/10.17113/ftb.55.02.17.4786

25. Li Y, Xu C, Lin X, Cui B, Wu R, Pang X. De novo assembly and characterization of the fruit transcriptome of Chinese jujube (Ziziphus jujuba Mill.) using 454 pyrosequencing and the development of novel tri-nucleotide SSR markers. PLoS ONE. 2014;9(9):e106438.

https://doi.org/10.1371/journal.pone.0106438

26. Schuelke M. An economic method for the fluorescent labelling of PCR fragments. Nat Biotechnol. 2000;18:233-4.

https://doi.org/10.1038/72708
27. GeneMapper v. 4.1, Applied BiosystemsTM, Thermo Fisher Scientific, Foster City, CA, USA. Available from: https://www. thermofisher.com/order/catalog/product/4366925.

28. Kalinowski ST, Taper ML, Marshall TC. Revising how the computer program CERVUS accommodates genotyping error increases success in paternity assignment. Mol Ecol. 2007;16:1099-106.

https://doi.org/10.1111/j.1365-294X.2007.03089.x

29. Wagner HW, Sefc KM. IDENTITY 1.0, Centre for Applied Genetics, University of Agricultural Sciences, Vienna, Austria; 1999.

30. Rohlf FJ. NTSYSpc: Numerical taxonomy and multivariate analysis system, v. 2.02, Applied Biostatistics Inc., Port Jefferson, NY, USA; 1998.

31. AOAC Official Method 950.46. Moisture in meat. Rockville, MD, USA: AOAC International; 1997.

32. Hach CC, Bowden BK, Kopelove AB, Brayton SV. More powerful peroxide Kjeldahl digestion method. J AOAC Int. 1987;70783-7.

33. Lee SC, Prosky L, De Vries JW. Determination of total, soluble, and insoluble dietary fiber in foods - enzymatic gravimetric method, MES-TRIS buffer - collaborative study. J AOAC Int. 1992;75395-416.

34. Vekemans B, Janssens K, Vincze L, Adams F, Van Espen P. Analysis of X-ray spectra by iterative least squares (AXIL): New developments. X-Ray Spectrom. 1994;23(6):278-85. https://doi.org/10.1002/xrs.1300230609

35. Nečemer $M$, Kump $P$, Ščančar J, Jaćimović $R$, Simčič J, Pelicon $\mathrm{P}$, et al. Application of X-ray fluorescence analytical techniques in phytoremediation. Spectrochim Acta Part B At Spectrosc. 2008;63(11):1240-7.

https://doi.org/10.1016/j.sab.2008.07.006

36. MassHunter WorkStation qualitative/quantitative analysis software B.05.00, Agilent Technologies, Waldbronn, Germany.

37. Klančnik A, Piskernik S, Jeršek B, Smole Možina S. Evaluation of diffusion and dilution methods to determine the antibacterial activity of plant extracts. J Microbiol Meth. 2010;81(2):121-6.

https://doi.org/10.1016/j.mimet.2010.02.004

38. CLSI M27-A3. Reference method for broth dilution antifungal susceptibility testing of yeasts. Wayne, PA, USA: Clinical and Laboratory Standards Institute (CLSI); 2008.

39. CLSI M38-A2. Reference method for broth dilution antifungal susceptibility testing of filamentous fungi. Wayne, PA, USA: Clinical and Laboratory Standards Institute (CLSI); 2008.

40. Stata Statistical Software, v. 13, StataCorp, College Station, TX, USA; 2013. Available from: https://www.stata.com.

41. Botstein D, White RL, Skolnick M, Davis RW. Construction of genetic linkage map in man using restriction fragment length polymorphisms. Am J Hum Genet. 1980;32(3):314-31. 
42. Yao S. Past, present, and future of jujubes-Chinese dates in the United States. Hortic Sci. 2013;48(6):672-80.

43. USDA National Nutrient Database for Standard Reference, release 27. Beltsville, MD, USA: US Department of Agriculture (USDA), Agricultural Research Service, Nutrient Data Laboratory; 2015. Available from: https://ndb.nal.usda.gov/ ndb.

44. Gao QH, Wu CS, Wang M. The jujube (Ziziphus jujuba Mill.) fruit: A review of current knowledge of fruit composition and health benefits. J Agric Food Chem. 2013;61(14):335163. https://doi.org/10.1021/jf4007032

45. Li JW, Fan LP, Ding SD, Ding XL. Nutritional composition of five cultivars of Chinese jujube. Food Chem. 2007;103(2):454-60.

https://doi.org/10.1016/j.foodchem.2006.08.016

46. Vidrih R, Ulrih NP, Zlatić E, Hribar J, Prgomet Z. The nutritional and physico-chemical properties of ripe (Ziziphus jujuba) fruits grown in Istria. Acta Hortic. 2009;840:525-8. https://doi.org/10.17660/ActaHortic.2009.840.74
47. Zhao J, Li SP, Yang FQ, Li P, Wang YT. Simultaneous determination of saponins and fatty acids in Ziziphus jujuba (Suanzaoren) by high performance liquid chromatography-evaporative light scattering detection and pressurized liquid extraction. J Chromatogr A. 2006;1108(2):188-94.

https://doi.org/10.1016/j.chroma.2005.12.104

48. San B, Yildirim AN. Phenolic, alpha-tocopherol, beta-carotene and fatty acid composition of four promising jujube (Ziziphus jujuba Miller) selections. J Food Compos Anal. 2010;23(7):706-10.

https://doi.org/10.1016/j.jfca.2010.02.008

49. Connor AM, Luby JJ, Hancock JF, Berkheimer S, Hanson EJ. Changes in fruit antioxidant activity among blueberry cultivars during cold-temperature storage. J Agric Food Chem. 2002;50(4):893-8.

https://doi.org/10.1021/jf011212y

50. Robards K, Prenzler PD, Tucker G, Swatsitang P, Glover W. Phenolic compounds and their role in oxidative processes in fruits. Food Chem. 1999;66(4):401-36. https://doi.org/10.1016/S0308-8146(99)00093-X 